Article

\title{
Production of Recombinant African Swine Fever Viruses: Speeding Up the Process
}

\author{
Anusyah Rathakrishnan, Katy Moffat, Ana Luisa Reis and Linda K. Dixon *(D) \\ The Pirbright Institute, Ash Road, Pirbright, Surrey GU24 0NF, UK; \\ anusyah.rathakrishnan@pirbright.ac.uk (A.R.); Kathryn.Moffat@pirbright.ac.uk (K.M.); \\ ana.reis@pirbright.ac.uk (A.L.R.) \\ * Correspondence: linda.dixon@pirbright.ac.uk
}

Received: 30 April 2020; Accepted: 3 June 2020; Published: 5 June 2020

check for updates

\begin{abstract}
African swine fever (ASF) is a devastating disease in pigs, with no vaccines for control. The genetic manipulation of African swine fever virus (ASFV) is often tedious and time consuming. Here, we describe a method to manipulate the virus genome to produce gene deletion viruses in a much-reduced time. This method combines the conventional homologous recombination with fluorescent-activated cells sorting (FACS), to isolate and purify viruses expressing fluorescent reporter genes. With three rounds of single cell isolation via FACS and two rounds of limiting dilution, we deleted two additional genes, EP153R and EP402R, from Benin 97/1 ASFV lacking the DP148R gene. By combining different fluorescent markers, this method has the potential to greatly facilitate studies on understanding ASFV gene functions and develop candidate live-attenuated vaccines.
\end{abstract}

Keywords: ASFV; FACS; recombinant virus; EP153R; EP402R; DP148R

\section{Introduction}

African swine fever virus (ASFV), the sole member of the family Asfaviridae, causes African swine fever (ASF) disease in European wild boar and domestic pigs. With lethality rates reaching $100 \%$ after infection with virulent ASFV strains, the acute form of disease is characterized by fever, loss of appetite, lethargy and haemorrhage. The less virulent strains can lead to mild clinical signs, subacute forms of disease, or even chronic infections. Warthogs and bush pigs develop mild or no clinical signs, even when infected with highly virulent isolates and, thus, they can act as reservoirs for infection [1].

ASF is endemic in many sub-Saharan African countries. Since 2007, countries in Eastern Europe, and more recently, at least 11 countries in Asia have reported numerous ASF outbreaks. ASF has a huge socio-economic impact, as pigs are important sources of protein. China is among the world's largest producers and consumers of pork and pork-related products. ASFV infection in these countries has thus led to destabilization of the pork industry throughout the world [2].

ASFV is either transmitted directly between animals or indirectly via feeding of infected meat or by products, or through fomites. Therefore, controlling ASF relies heavily on zoning or restricting movement of animals, the immediate culling of pigs in infected areas and rigorous surveillance. No vaccines nor antivirals exist for ASF, mainly due to the gap in knowledge regarding ASFV, including (i) the unknown functions of at least half of the encoded 150-167 proteins; (ii) the absence of correlates of protection and a general poor understanding of protective immunity; and (iii) the need for primary cells to propagate and manipulate the virus $[3,4]$.

Rational deletions of ASFV virulence genes or immune response inhibitory genes, is often seen as the fastest route to vaccine development [3]. Serial gene deletions allow optimization of safety and efficacy of recombinant live attenuated vaccines (LAVs). However, producing these viruses with multiple gene deletions remains a major bottleneck since deleting a single gene can take up to 
3-4 months. Conventionally, genetic manipulation of ASFV for producing LAV candidates or for gene function studies have relied on using homologous recombination, whereby ASFV genes are replaced with a reporter gene including $\beta$-galactosidase ( $\beta$-Gal) or $\beta$-glucuronidase (GUS) [5-9] or more recently, fluorescent reporter genes [10-14]. Using the Cre/ loxP recombination system, sequential deletion of multiple ASFV genes has been performed to allow the same reporter genes to be used several times. However, this requires additional steps and therefore extended production time [15]. Homologous recombination events are rare, and to improve this initial efficiency, Borca and colleagues applied the CRISPR/Cas9 system to facilitate gene deletion [16]. Nevertheless, the subsequent steps involve multiple rounds of limiting dilution or plaque purification to obtain recombinant viruses, without contamination from the parental virus. This makes the overall production of gene deleted ASFV a long process.

Here, we describe a method to speed up the production of recombinant ASFV by taking advantage of fluorescent reporter markers and single cell isolation fluorescence-activated cell sorting (FACS). The time to make deletions has been shortened from 3-4 months to 1-1.5 months using this method. This, combined with the ability to use at least three different fluorescent reporter genes simultaneously, can positively contribute to the production of recombinant ASFV that can be used as vaccine candidates and to study viral gene functions.

\section{Materials and Methods}

\subsection{Cells and Viruses}

Spontaneously immortalized wild boar cell line, WSL-R was kindly provided by Dr. Walter Fuchs (Friedrich-Loeffler-Institut, Greifswald-Insel Riems, Germany) and grown in ZB28 medium (50\%

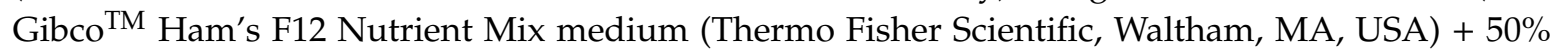
Gibco $^{\mathrm{TM}}$ IMDM) supplemented with $10 \%$ fetal bovine serum (FBS) (Life Science Production, Bedford, UK), $1 \%$ Gibco $^{\mathrm{TM}}$ Penicillin-Streptomycin, and 1\% Gibco ${ }^{\mathrm{TM}}$ Glutamine. Primary porcine bone marrow cells (PBMs) were derived from the long leg bones of 4-week-old outbred pigs, and were maintained in Gibco ${ }^{\mathrm{TM}}$ EBSS supplemented with $10 \%$ porcine serum (Biosera, Nuaille, France), $1 \%$ Penicillin-Streptomycin and $1 \%$ Gibco ${ }^{\text {TM }}$ HEPES. Additionally, PBMs were centrifuged at $1000 \mathrm{~g}$ for $30 \mathrm{~min}$ on a density gradient at $1.083 \mathrm{~g} / \mathrm{mL}$ in Histopaque (Sigma-Aldrich, Dorset, UK). The buffy coat was collected, red blood cells lysed with 1X RBC Lysis Buffer (BioLegend, San Diego, CA, USA) and washed with PBS, to obtain purified PBMs that could be frozen down in freezing medium constituted of $90 \%$ FBS and 10\% DMSO (Sigma-Aldrich, Dorset, UK). Thawed purified PBMs were maintained in RPMI 1640 medium, supplemented with Gibco ${ }^{\mathrm{TM}}$ Glutamax, 10\% FBS, $1 \%$ Penicillin-Streptomycin and $100 \mathrm{ng} / \mathrm{mL}$ of recombinant porcine macrophage colony-stimulating factor (CSF1) (Roslin Technologies, Midlothian, UK).

ASFV isolates used in this study include Benin 97/1 (genotype I) [17], Benin $\triangle$ DP148R [18] and Benin $\triangle E P 402 R$ (unpublished data). Propagation and titrations of virus were carried out using PBMs or purified PBMs. Virus titrations were carried out by endpoint dilution assays either via haemadsorption $\left(\mathrm{HAD}_{50} / \mathrm{mL}\right)[19]$ or by detection of infected fluorescent cells $\left(\mathrm{TCID}_{50} / \mathrm{mL}\right)$. Virus titres were calculated using the Spearman and Kärber algorithm [20].

\subsection{Production of Recombinant ASFV Benin $\triangle E P 153 R \triangle E P 402 R \triangle D P 148 R$}

We aimed to produce a recombinant ASFV from previously published attenuated Benin $\triangle \mathrm{DP} 148 \mathrm{R}$ by further deleting the genes EP153R and EP402R. We combined the conventional homologous recombination with single cell isolation via FACS to produce a final recombinant Benin $\triangle \mathrm{EP} 153 \mathrm{R} \Delta \mathrm{EP} 402 \mathrm{R} \Delta \mathrm{DP} 148 \mathrm{R}$. 


\subsubsection{Transfer Plasmid}

A donor/transfer plasmid containing: (i) the $\mathrm{mNeonGreen} \mathrm{fluorescent} \mathrm{reporter} \mathrm{gene} \mathrm{[21],} \mathrm{under} \mathrm{the}$ control of the ASFV VP30 (CP204L) promoter [22]; (ii) approximately $0.8 \mathrm{kbp}$ left flanking arm of ASFV EP153R; and (iii) $0.8 \mathrm{kbp}$ right flanking region of ASFV EP402R, was synthesized from the Benin 97/1 isolate (GenScript, Leiden, the Netherlands) (Figure 1A). The whole fragment (2478 bp) was cloned in pUC57, using the proprietary CloneEZ ${ }^{\circledR}$ Seamless cloning technology with restriction sites EcoRI/ HindIII and verified via restriction digestion, vector and target sequencing. Plasmid DNA was transformed in DH5 $\alpha$ E. coli and was extracted using QIAGEN Plasmid Midi Kit (Qiagen, Hilden, Germany), according to the manufacturer's instructions.

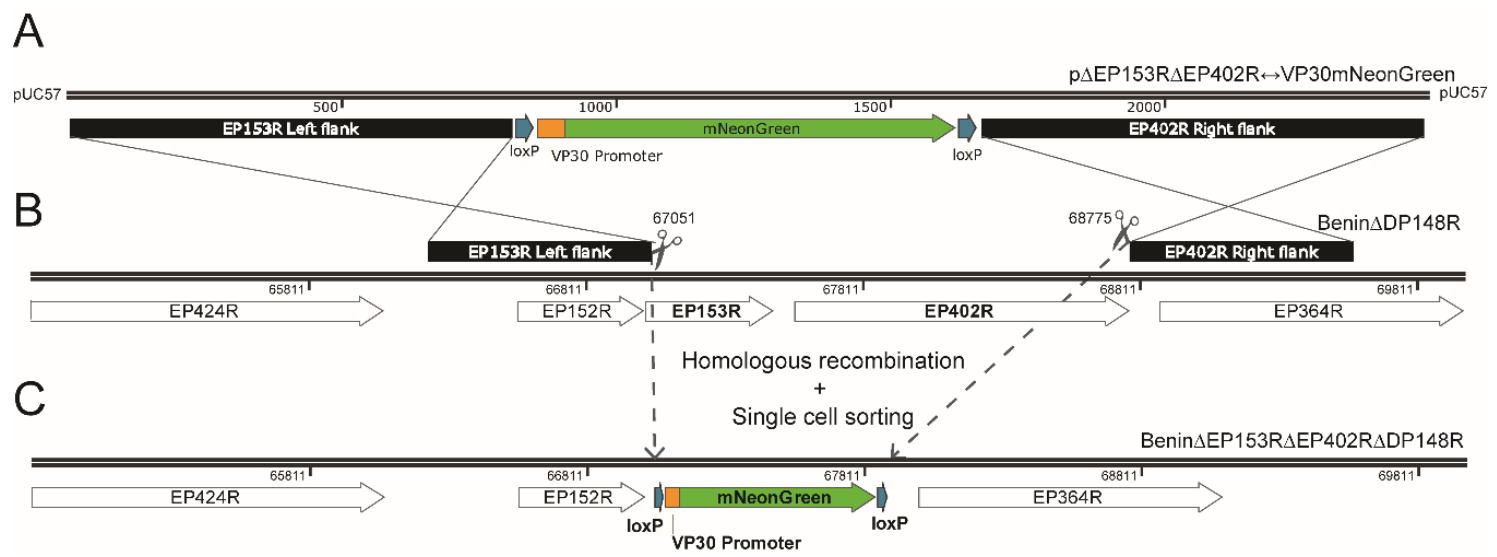

Figure 1. Schematic diagram depicting the generation of recombinant African swine fever (ASFV) isolate lacking genes EP153R and EP402R using homologous recombination and single cell sorting. Homologous recombination between transfer plasmid $\mathrm{p} \Delta \mathrm{EP} 153 \mathrm{R} \Delta \mathrm{EP} 402 \mathrm{R} \leftrightarrow \mathrm{VP} 30 \mathrm{mNeonGreen}(\mathbf{A})$ and parental Benin $\triangle \mathrm{DP148R}$ (B) removed genes EP153R and EP402R (genome position: 67,051 to 68,775) from parental virus and replaced with a VP30mNeonGreen reporter gene cassette from the transfer plasmid to generate Benin $\triangle \mathrm{EP} 153 \mathrm{R} \triangle \mathrm{EP} 402 \mathrm{R} \Delta \mathrm{DP} 148 \mathrm{R}$ (C). Gene maps were copied from SnapGeneßViewer software (GSL Biotech, San Diego, CA, USA; available at snapgene.com) and modified on Adobe ${ }^{\circledR}$ Illustrator ${ }^{\circledR}$ CS6 (Adobe Systems Inc., San Jose, CA, USA).

\subsubsection{Homologous Recombination-Infection/Transfection}

WSL-R cells were infected with Benin $\triangle \mathrm{DP} 148 \mathrm{R}$ [18] at the multiplicity of infection (MOI) of 2, and plates were centrifuged at $600 \mathrm{~g}$ for $1 \mathrm{~h}$. After $3 \mathrm{~h}$ of incubation at $37^{\circ} \mathrm{C}$, transfection mixture containing Gibco ${ }^{\mathrm{TM}}$ OptiMEM, $500 \mathrm{ng}$ of transfer plasmid (2.2.1) and TransIT-LT1 (Mirus Bio, Madison, WI, USA) was added to the infected cells, and centrifuged again at $600 \mathrm{~g}$ for an hour. Infected/ transfected cells were incubated at $37^{\circ} \mathrm{C}, 5 \% \mathrm{CO}_{2}$ for $48 \mathrm{~h}$.

\subsubsection{Single Cell Isolation via FACS}

The infected/ transfected cells were harvested and pooled after $48 \mathrm{~h}$. The cells were washed and re-suspended at $3 \times 10^{5}$ cells $/ \mathrm{mL}$ in chilled sterile FACS buffer $\left(\mathrm{CaCl}_{2}\right.$ and $\mathrm{MgCl}_{2}$ free-Dulbecco's PBS supplemented with $5 \mathrm{mM}$ EDTA, $25 \mathrm{mM}$ HEPES and 1\% FBS) and passed through a $70 \mu \mathrm{m}$ cell strainer (BD Biosciences, San Jose, CA, USA) prior to cell sorting.

For single cell sorting, we used DIVA8 acquisition software with a FACSAria Fusion cell sorter (BD Biosciences) equipped with a $405 \mathrm{~nm}$ (violet), $488 \mathrm{~nm}$ (blue), $561 \mathrm{~nm}$ (yellow green) and $640 \mathrm{~nm}$ (red) laser. Specifically, for producing Benin $\Delta \mathrm{EP} 153 \mathrm{R} \Delta \mathrm{EP} 402 \mathrm{R} \Delta \mathrm{DP} 148 \mathrm{R}$, the mNeonGreen infected-transfected cells were detected with a blue 530/30 BP filter and the violet 450/40 BP signal was collected and used to gate out autofluorescent cells. In sorts where viruses with a red fluorescent protein was used as a reporter, a yellow/green 582/15 BP filter was used to detect the fluorescence. Sorting was done with the $85 \mu \mathrm{m}$ nozzle at $45 \mathrm{psi}$ and in single cell precision mode. To sterilize 
the flow cytometer between sorts, $2.3 \%$ sodium hypochlorite was run at a flow rate of 5 , for 5 min, as recommended by OIE [23].

The FACS gating strategy to identify virus infected-transfected cells is shown in Figure 2. In brief, samples were gated based on cell size/granularity (SSC-A vs. FSC-A) and singlets (SSC-H vs. SSC-A), autofluorescent cells were identified as being dual positive for violet and mNeonGreen and were excluded. Virus infected-transfected cells were then identified as single positive for mNeonGreen. Single color controls were used for compensation and non-infected or non-transfected controls were used to set thresholds (Figures S1 and S2)

The cells were collected at single cell density into individual wells of Thermo Scientific ${ }^{\mathrm{TM}} \mathrm{Nunc}^{\mathrm{TM}}$ MicroWell ${ }^{\mathrm{TM}}$ 96-Well microplates (Thermo Fisher Scientific), containing $5 \times 10^{5}$ purified PBMs in $100 \mu \mathrm{L}$ media. The microplates were then incubated at $37^{\circ} \mathrm{C}, 5 \% \mathrm{CO}_{2}$ for 5 days. Cultures were then monitored for expression of $\mathrm{mNeonGreen} \mathrm{under} \mathrm{an} \mathrm{inverted} \mathrm{fluorescent} \mathrm{microscope} \mathrm{(Olympus} \mathrm{CKX41;}$ Olympus, Tokyo, Japan).

To purify recombinant ASFV, now with additional EP153R and EP402R genes deleted and replaced with reporter gene mNeonGreen, wells in which fluorescent cells were observed were harvested individually, washed and re-suspended in FACS buffer. The cells were passed through a $70 \mu \mathrm{m}$ cell strainer, and then subjected to another round of single cell isolation via FACS, just as described above. A final round of single cell sorting was performed 5 days later.

\subsubsection{Viral Genomic DNA Extraction and PCRs}

Wells containing fluorescent cells were selected for viral genomic DNA extraction using the MagVet $^{\mathrm{TM}}$ Universal Isolation Kit (Thermo Fisher Scientific, Waltham, MA, USA), according to the manufacturer's protocol, with minor modifications, including the use of a $40 \mu \mathrm{L}$ instead of a $100 \mu \mathrm{L}$ initial test sample, and the final elution in $60 \mu \mathrm{L}$ of Elution Buffer NM6 instead of the recommended $80 \mu \mathrm{L}$. The lysed samples were extracted on the high-throughput KingFisher ${ }^{\mathrm{TM}}$ Flex Extraction System (Thermo Fisher Scientific, Waltham, MA, USA), using programmed script NM_LSI_RRC96. Extracted viral DNA was then subjected to PCR amplification to confirm the intended deletions, to verify the absence of carry-over parental virus and the presence of the fluorescent reporter gene (Table 1). The viral genomic DNA extraction and PCR amplifications were repeated after the limiting dilutions steps and the final virus propagation.

Table 1. Primers used in evaluating the absence or presence of target genes.

\begin{tabular}{|c|c|c|c|}
\hline Gene Target & Primer Sequence $\left(5^{\prime}-3^{\prime}\right)$ & Genome Position a & $\begin{array}{c}\text { Expected PCR } \\
\text { Product Size }\left(b^{b}{ }^{b}\right)\end{array}$ \\
\hline \multicolumn{4}{|l|}{ DP148R } \\
\hline Forward & GTCCGCAACAAGGCTATTGAG & \multirow{2}{*}{$178,296-178,602$} & \multirow{2}{*}{307} \\
\hline Reverse & GACGTTTACGCAGTGGGGC & & \\
\hline \multicolumn{4}{|l|}{ EP153R } \\
\hline Forward & GATTGGAACTAATATGATAACTC & \multirow{2}{*}{$67,137-67,433$} & \multirow{2}{*}{297} \\
\hline Reverse & TCACCACGTAATATTACCGT & & \\
\hline \multicolumn{4}{|l|}{ EP402R } \\
\hline Forward & GTTCATGTTGTGGTCATAACATATC & \multirow[b]{2}{*}{$67,763-68,365$} & \multirow[b]{2}{*}{603} \\
\hline Reverse & GAGATGGTTCATGTATGGAAGTG & & \\
\hline \multicolumn{4}{|l|}{ GUS } \\
\hline Forward & GGTCCGTCCTGTAGAAACCCCAA & \multirow{2}{*}{-} & \multirow{2}{*}{907} \\
\hline Reverse & GCCACGCAAGTCCGCATCTTCATG & & \\
\hline \multicolumn{4}{|l|}{ mNeonGreen } \\
\hline Forward & TACACATCTTTGGCTCCATC & \multirow[t]{2}{*}{ - } & \multirow{2}{*}{634} \\
\hline Reverse & CCCATCACATCGGTAAAGG & & \\
\hline
\end{tabular}


A

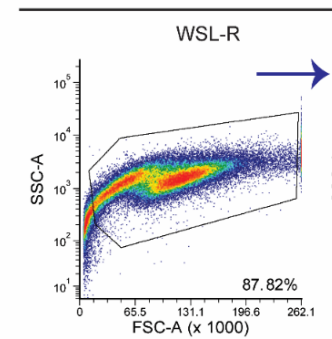

B

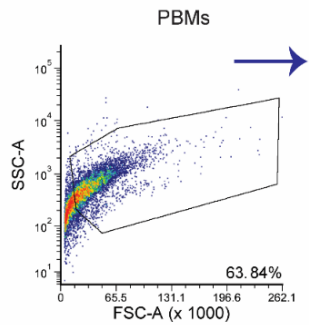

PBMs

C

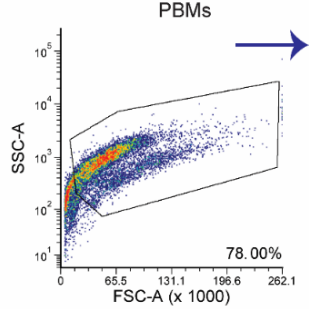

Pre-sort

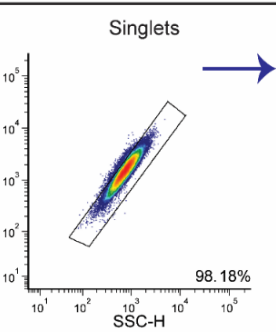

Singlets
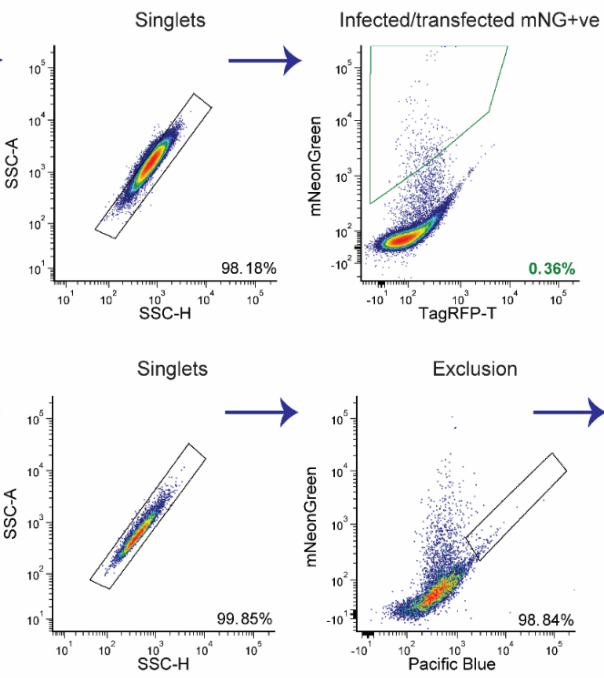

Infected mNG+ve
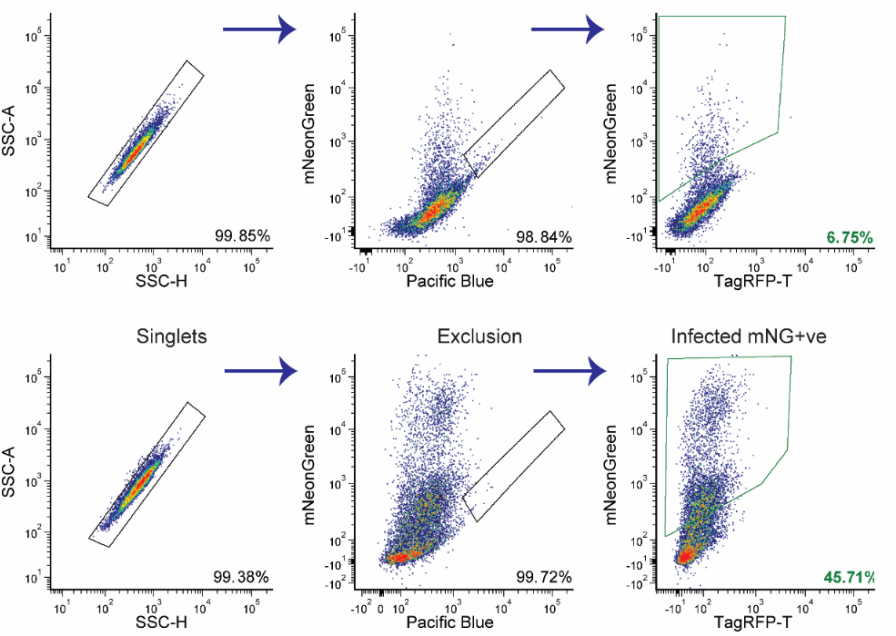
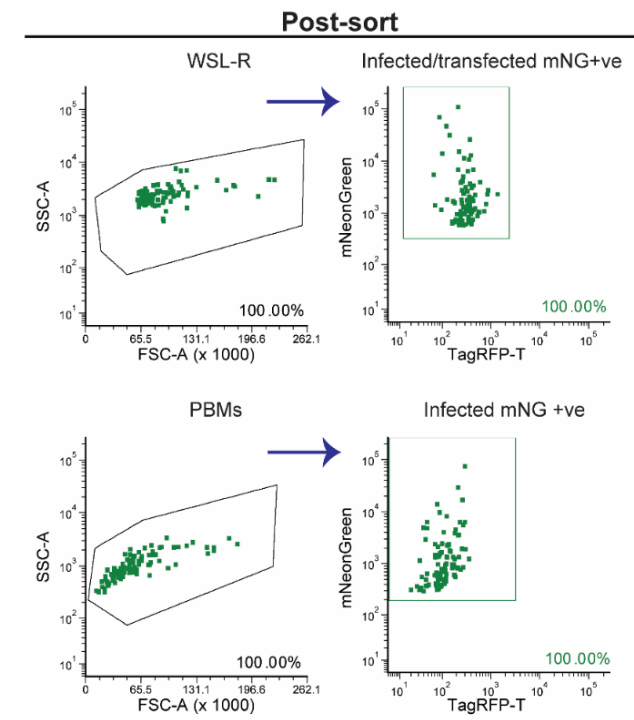

Infected mNG +ve
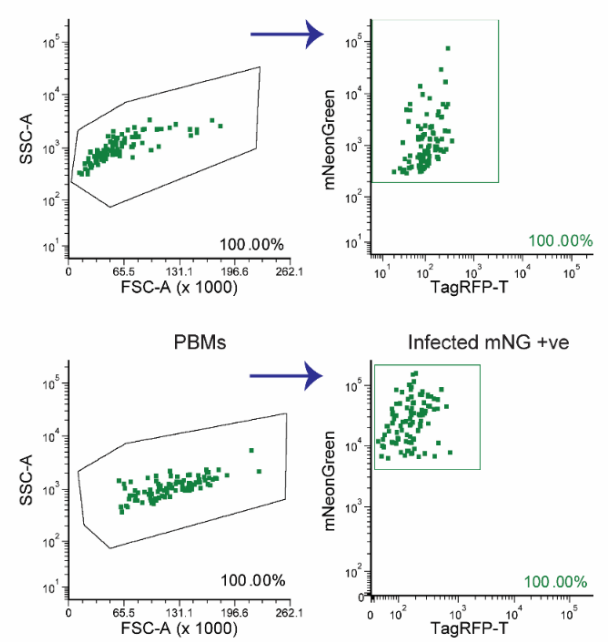

Figure 2. Purification of recombinant Benin $\triangle E P 153 R \triangle E P 402 R \triangle D P 148 R$ via single cell isolation using FACS. The biparametric flow cytometry profiles depicted include two phases. Phase 1-pre-sorting: Panel 1-SSC-A vs FSC-A for total cells; Panel 2-SSC-A vs. SSC-H to obtain singlets; Panel 3-blue BP 530/30 nm-A vs. violet BP 450/40 nm-A to exclude autofluorescence cells, prominently in porcine bone marrow cells (PBMs); Panel 4-blue BP 530/30 nm-A vs. yellow-green (YG) BP 582/15nm-A to capture the mNeonGreen ( $\mathrm{mNG}$ ) positive cell subpopulation. Phase 2-post-sorting: Panel 5-total cells that were single cell sorted into 96-well plate containing purified PBMs; Panel 6-each dot represents an individual mNG positive cell that was sorted. The flow cytometry profiles are shown for (A) after the homologous recombination event in WSL-R cells; (B) second round of single cell sorting of recombinant ASFV-infected PBMs from a single mNG positive well, monitored under a fluorescent microscope; (C) third round of single cell isolation of a single mNG positive well, similar to (B), except the gating for mNG positive subpopulation was more stringent to capture the brighter selection of cells for single cell isolation. The percentages in each panel reflect the percentage of cells within that gate relative to the parent gate. 


\subsubsection{Limiting Dilutions, Propagations and Titrations}

Wells containing fluorescent cells with the desired gene-deleted virus were subjected to 2 rounds of limiting dilutions. The recombinant virus was then propagated in purified PBMs and titrated. Finally, viral genomic DNA flanking the whole recombination site was amplified to confirm the correct deletion. Briefly, viral DNA was extracted using the QIAamp Viral RNA Mini Kit (Qiagen, Hilden, Germany). The isolated DNA was amplified using proofreading $Q 5^{\circledR}$ high-fidelity DNA polymerase (NEB, Hertfordshire, UK) (Table 2), and electrophoresed on $0.8 \%$ agarose gel.

Table 2. Primers used for sequencing the recombinant Benin $\Delta$ EP153R $\Delta E P 402 R \Delta D P 148 R$.

\begin{tabular}{ccc}
\hline Primer Name & Primer Sequence (5' $\mathbf{~} \mathbf{3}^{\prime} \mathbf{)}$ & Genome Position $^{\text {a }}$ \\
\hline Del_EP153R_CD2v-SeqF1 & CTTTGCCGTAGAAACAATACA & 65,867 \\
Del_EP153R_CD2v-SeqR3 & TCAGGCTGTGTTCAATAA & 69,978 \\
mNG_SeqR & CCATGTCAAAGTCCACACCG & - \\
mNG_SeqF & CCAATGGCGGCTAACTATCTG & - \\
\hline a Genome position is based on Benin 97/1 isolate. The - indicates that primers do not bind anywhere in Benin 97/1.
\end{tabular}

\section{Results and Discussion}

FACS enables the sorting of a heterogeneous cell population into a relatively homogenous population, depending on their light scatters and fluorescent features. This technology has contributed greatly to understanding virus infections from identifying virus susceptible cells, characterizing viral protein expression, to defining host immune responses. Here, we combine homologous recombination and sorting of single cells infected with ASFV, expressing a fluorescent protein, to rapidly purify a genetically modified ASFV, Benin $\triangle \mathrm{EP} 153 \mathrm{R} \Delta \mathrm{EP} 402 \mathrm{R} \Delta \mathrm{DP} 148 \mathrm{R}$ (Figure 1C).

The parental Benin 97/1 isolate with DP148R gene deleted and replaced with GUS reporter has been previously described [18] (Figure 1B). The transfer plasmid p $\Delta E P 153 R \Delta E P 402 R \leftrightarrow V P 30 m N G$ contains: (i) a fluorescent reporter gene: mNeonGreen (mNG) under the control of ASFV P30 promoter (5'-TTATTATTTTATAATTTTAAAATTGAATGGATTTTATTTTAAATATATCC); (ii) left flanking arm of EP153R (Benin 97/1 genomic positions 66,245-67,050); and (iii) right flanking arm of EP402R (Benin 97/1 genomic positions 68,776-69,580), all cloned into pUC57 vector (Figure 1A). The ASFV VP30 promoter was selected because P30 (CP204L) is expressed at both early and late stages of infection, and its promoter was shown to equally promote reporter gene expression in recombinant ASFV from early to late phases of infection [22]. Using this construct, 21bp of EP153R at the $5^{\prime}$ end remain in the recombinant virus, as it may contain the transcription termination signal for the adjacent EP152R gene [24,25].

Primary macrophages have a very low transfection efficiency [26,27], therefore, to increase the efficiency of recombination, the wild boar cell line, WSL-R, known to be ASFV susceptible [11,28,29], was used in the first step of producing the recombinant virus. WSL-R cells were infected with Benin $\triangle \mathrm{DP} 148 \mathrm{R}$, and then transfected with $\mathrm{p} \Delta \mathrm{EP} 153 \mathrm{R} \Delta \mathrm{EP} 402 \mathrm{R} \leftrightarrow \mathrm{VP} 30 \mathrm{mNG}$. A centrifugation step at $600 \mathrm{~g}$ for $1 \mathrm{~h}$ after both the infection and transfection steps was included to increase the recombination efficiency, as this was shown to enhance retroviral transductions [30] and improve liposome mediated transfections [31].

Cell preparation for live cell sorting is important to maintain cell integrity. To reduce the stress on cells, $48 \mathrm{~h}$ post-infection and transfection, the following measures were implemented: (i) keeping cells cold throughout the experiment; (ii) the removal of supernatant and two washes to minimize extracellular virus and debris; (iii) minimal centrifugation speed (300 $g$ ) to sediment cells; and (iv) usage of FACS buffer that contains $\mathrm{Ca}^{2+} / \mathrm{Mg}^{2+}$ free PBS to reduce cell aggregation, EDTA to prevent cell adhesion and HEPES to improve buffer capacity during sorting. The cell morphology of infected-transfected cells was observed via the biparametric FSC vs. SSC profile (Figures 2 and S1, Panel 1). The overall morphological differences between unmodified cells (Figure S1A, Panel 1), transfer plasmid transfected cells (Figure S1B, Panel 1), Benin $\triangle \mathrm{DP} 148 \mathrm{R}$ (parental virus) and an additional 
fluorescent ASFV -infected cells (Figure S1C,D, Panel 1) were minimal. The FSC threshold was set to $5 \mathrm{~K}$, so that debris would be detected and excluded during live cell sort. FACS of single mNeonGreen expressing cells was done with an $85 \mu \mathrm{m}$ nozzle at 45 psi, to reduce additional stress on cells. The sorted single cell was eventually expected to release the recombinant virus into the fresh PBMs and, therefore, the initial gating included all possible cell fractions including potentially dead cells (Figure 2A, Panel 1).

Flow cytometric analysis at $48 \mathrm{~h}$ post-infection/transfection showed that approximately $0.31 \%$ of the cells were positive for $\mathrm{mNeonGreen,} \mathrm{representing} \mathrm{cells} \mathrm{that} \mathrm{are} \mathrm{potentially} \mathrm{infected} \mathrm{with} \mathrm{recombinant}$ viruses (Figure 2A). Using the same method to prepare other recombinant viruses, we obtained approximately $0.1 \%$ to $3.0 \%$ of infected and transfected WSL-R cells. The mNeonGreen expressing population was then single cell sorted via FACS into individual wells of a 96-well plate containing purified PBMs. Despite sorting only single mNeonGreen positive cells, 5 days later, only $8.1 \%$ of wells when observed under a fluorescent microscope were positive for mNeonGreen. This phenomenon could either be associated with absence of homologous recombination in most of the cells or an abortive replication cycle in WSL-R cells. Hence, at least two or three steps of single cell isolation of mNeonGreen positive PBMs were necessary to obtain a pure recombinant virus culture with no parental virus contamination.

In the second round of FACS, cells were harvested from individual wells, in order to trace the virus population to the original single infected/transfected cell. The percentage of mNeonGreen expressing cells ranged from $0.71 \%$ to $4.45 \%$ of the total cell population (Figure $2 \mathrm{~B}$; Table S1). The relatively low percentage of $\mathrm{mNeonGreen} \mathrm{expressing} \mathrm{cells} \mathrm{could} \mathrm{be} \mathrm{due} \mathrm{to} \mathrm{the} \mathrm{competing} \mathrm{presence} \mathrm{of} \mathrm{the}$ parental Benin $\triangle \mathrm{DP} 148 \mathrm{R}$. Single cells from the mNeonGreen positive population were sorted for a second time into plates containing purified PBMs. At five days post-infection, the percentage of wells that contained cells infected with the recombinant fluorescent virus increased to a range of 40.6-53.1\% (Table S2). Cells from twelve mNeonGreen positive wells were then evaluated by flow cytometry, and the proportion of total cells infected with recombinant fluorescent virus ranged from $22.2-59.5 \%$ (Figure 2C, Table S1). This increase of approximately 10-80\% in the proportion of PBMs expressing mNeonGreen, as compared to the previous round of FACS analysis, indicates increased purity with a lower contamination from parental virus. In order to further purify the recombinant Benin $\triangle \mathrm{EP} 153 \mathrm{R} \Delta \mathrm{EP} 402 \mathrm{R} \Delta \mathrm{DP} 148 \mathrm{R}$ population, the final gating stringency was increased, so that only cells expressing $\mathrm{mNeonGreen}$ at a mean fluorescent intensity (MFI) above $5 \times 10^{3}$ were single cell sorted into purified PBMs (Figure 2C, Panel 6). As expected, the number of sorted wells that were positive with $\mathrm{mNeonGreen} \mathrm{expressing} \mathrm{PBMs,} \mathrm{when} \mathrm{monitored} \mathrm{under} \mathrm{a} \mathrm{fluorescent} \mathrm{microscope,} \mathrm{dramatically}$ increased to a range of $71.8-90.6 \%$ (Table S2).

The gradual increase in both the percentages of the total PBM population expressing mNeonGreen (1st round: $0.31 \%$; 2nd round: $0.71-4.45 \%$; 3rd round: $22.2-59.5 \%$ ) and number of wells containing mNeonGreen positive cells (1st post-sort: 8.1\%; 2nd post-sort: 40.6-53.1\%; 3rd post-sort: $71.8-90.6 \%$ ) over the rounds of single cell sorting reflects the enhanced purity of the Benin $\triangle E P 153 R \triangle E P 402 R \Delta D P 148 R$ recombinant virus. PCR analysis showed that fragments corresponding to the EP153R and EP402R genes were not amplified, but the mNeonGreen reporter gene fragment was amplified from sixty percent of the wells containing $\mathrm{mNeonGreen}$ expressing cells. This indicates that a pure population of recombinant virus, without contaminating the parental virus, may be obtained by the third round of single cell sorting. However, two rounds of limiting dilution were performed to ensure the recombinant virus was completely free of parental virus. PCR analyses of DNA extracted from all wells containing cells infected with mNeonGreen expressing recombinant virus showed that, as expected, fragments corresponding to the deleted genes were not amplified, as seen in Figure 3A-C (A: DP148R; B: EP153R; C: EP402R). Fragments from the GUS and mNeonGreen reporter insertions were amplified (Figure 3D,E). It was noted that, following the first round of limiting dilution, a pure population of the recombinant virus is usually obtained. Therefore, we recommend an additional round of single cell isolation, or at least one round of limiting dilution, is included when this method is used, to ensure the recombinant ASFV is pure. Lastly, PCR amplifications encompassing the 
whole recombination site were undertaken with primers that anneal outside the cloned left and right flanking regions, in combination with primers that bind within the mNeonGreen gene (Table 2) or to the EP153R and EP402R genes (Table 1). As expected, the amplified viral DNA of approximately $1377 \mathrm{bp}$ and $1395 \mathrm{bp}$ was detected in the recombinant virus and absent in the wildtype Benin 97/1 isolate when the mNeonGreen primers were used (Figure S3A,B). The internal primers for genes EP153R and EP402R failed to detect amplicons in the recombinant virus, but amplified viral DNA from the wild type virus (Figure S3C,D). This confirms that the gene deletion and insertion of the reporter cassette had occurred correctly, as these primers also do not bind to the transfer plasmid.
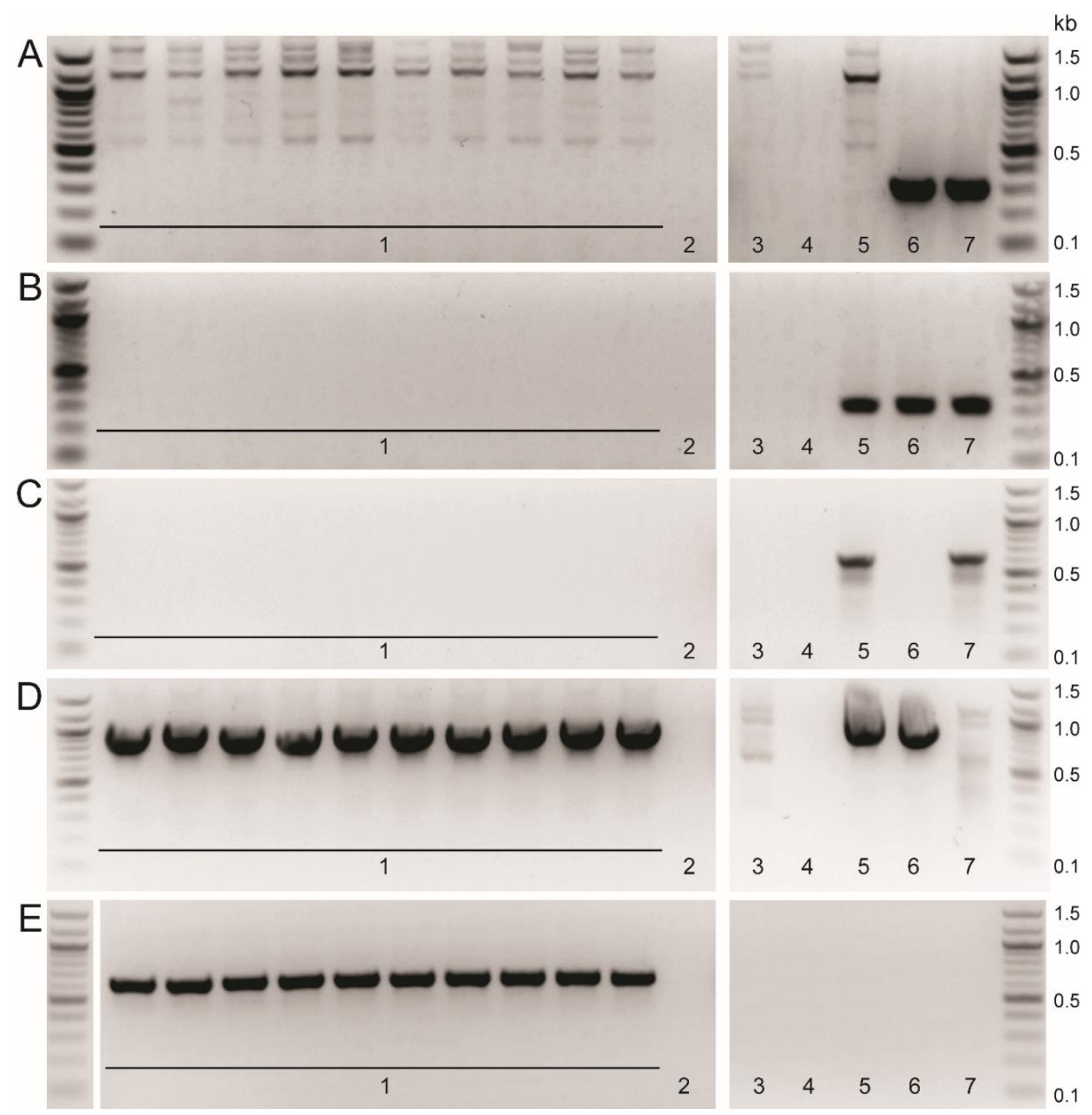

Figure 3. Representative PCR analyses of recombinant Benin $\triangle E P 153 R \Delta E P 402 R \Delta D P 148 R$ showing the successful deletions of genes EP153R and EP402R. The extracted genomic viral DNA was subjected to PCR amplification and analysed by electrophoresis on $1.5 \%$ agarose gels. Panel depicts results from amplification of genes (A) DP148R (307 bp); (B) EP153R (297 bp); (C) EP402R (603 bp), (D) GUS (907 bp) and (E) mNeonGreen (634 bp). Lanes numbered 1 show analysis of samples from individual wells of purified Benin $\triangle \mathrm{EP} 153 \mathrm{R} \Delta \mathrm{EP} 402 \mathrm{R} \Delta \mathrm{DP} 148 \mathrm{R}$ compared to (2) extraction negative control; (3) cell lysate control; (4) PCR negative control; (5) Benin $\triangle \mathrm{DP} 148 \mathrm{R}$ control; (6) Benin $\triangle E P 402 \mathrm{R}$ control and (7) wildtype Benin 97/1 control. 
The final titre of the newly produced recombinant Benin $\Delta$ EP153R $\Delta$ EP402R $\Delta$ DP148R (Figure 4) $\left(1.68 \times 10^{8} \mathrm{TCID}_{50} / \mathrm{mL}\right)$ was not significantly different compared to the titres of Benin 97/1 isolate $\left(1.78 \times 10^{7} \mathrm{HAD}_{50} / \mathrm{mL}\right)$ and the Benin $\triangle \mathrm{DP} 148 \mathrm{R}\left(5.62 \times 10^{7} \mathrm{HAD}_{50} / \mathrm{mL}\right)$, as expected. Both EP153R and EP402R have been previously deleted from various ASFV isolate singly [32-36]. Benin $\triangle E P 153 R \Delta E P 402 R \Delta D P 148 R$ is also non-haemadsorbing, compared to the virulent Benin 97/1 and attenuated Benin $\triangle \mathrm{DP} 148 \mathrm{R}$, which is expected, as EP402R (also known as CD2v) is responsible for haemadsorption [37] and ASFV isolates which have truncated or missing EP402R also cannot haemadsorb [38].
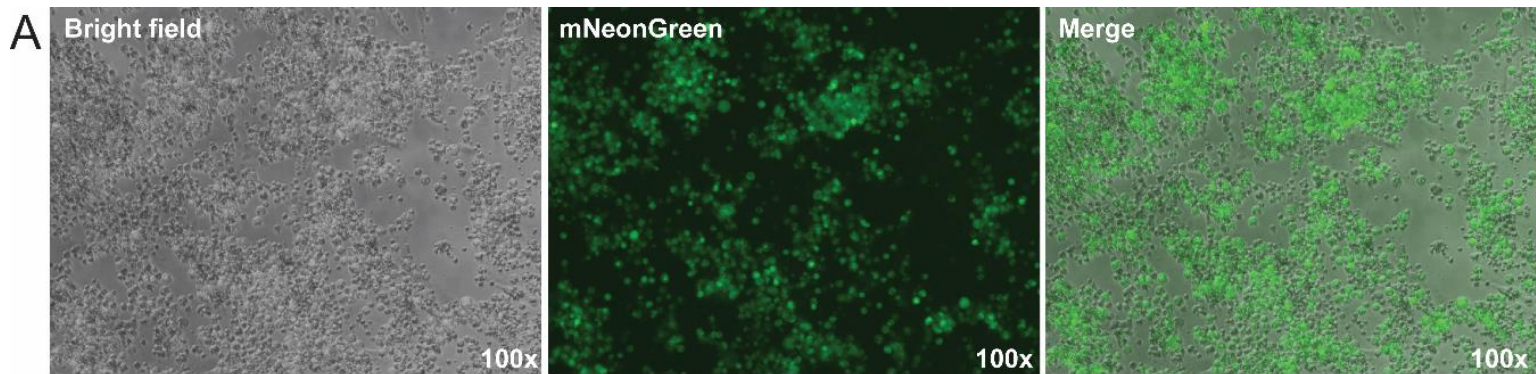

B

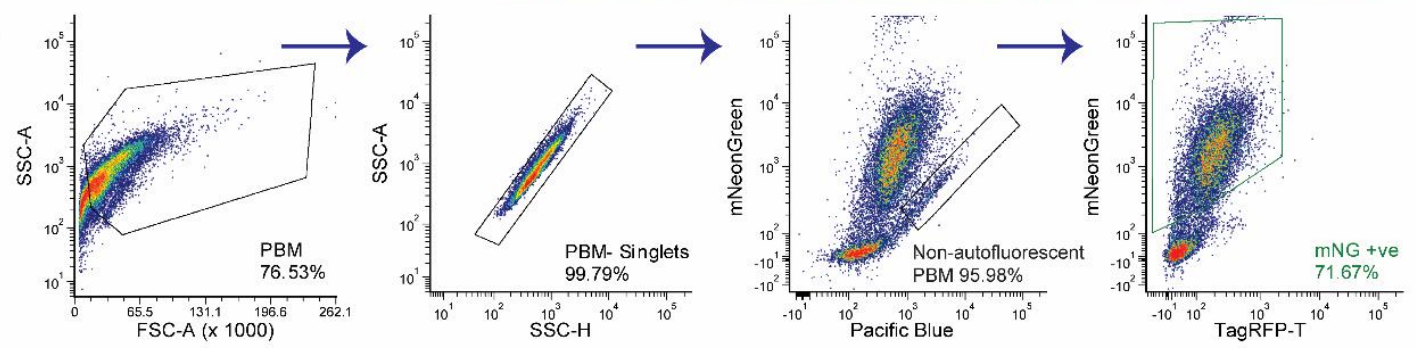

Figure 4. Primary bone marrow cells were infected with the produced recombinant ASFV Benin $\triangle E P 153 R \triangle E P 402 R \triangle D P 148 R$ at MOI of $1 . \quad$ (A) The images were taken 5 days post-infection, showing the bright field image of purified PBMs, the mNeonGreen expressed by Benin $\triangle$ EP153R $\triangle E P 402 R \Delta D P 148 R$-infected cells (green) and a merged image overlaying total purified PBMs with the infected PBMs. Magnifications are indicated in the images $(100 \times)$. Images were taken using the EXi Blue fluorescence microscopy camera and QCapture Pro Version 7 (QImaging, Tucson, AZ, USA). (B) The same recombinant ASFV-infected PBMs were analysed by flow cytometry, and the biparametric profiles leading to gating of $\mathrm{mNeonGreen} \mathrm{positive} \mathrm{cells} \mathrm{are} \mathrm{depicted.} \mathrm{Gating} \mathrm{strategy}$ to identify infected cells; Panel 1: SSC-A vs FSC-A for total cells; Panel 2: SSC-A vs. SSC-H to obtain singlets; Panel 3: blue BP 530/30 nm-A vs. violet BP 450/40 nm-A to exclude autofluorescence cells, finally blue BP 530/30 nm-A vs. Yellow-Green (YG) BP 582/15 nm-A (Panel 4) to capture the mNeonGreen (mNG) positive cell subpopulation.

Using this single cell isolation method, it is feasible to use at least three different fluorescent markers in a single ASFV isolate, considering the filters available on the fluorescent microscope used to monitor microtiter plates. We have created several recombinant ASFV mutants with deleted genes replaced with TagRFP-T [39] or both TagRFP-T and mNeonGreen. With the presence of loxP flanking the reporters in the recombinant mutants, in the future, these fluorescent genes can be removed or swapped, allowing the researchers more flexibility. Most importantly, the time to obtain pure recombinant ASFV has been shortened to 1 to 1.5 months using this method, compared to the 3 to 4 months required for making a single gene deletion using purification via limiting dilution. In addition, the positive selection by FACS can greatly facilitate isolation of recombinant viruses that have a growth defect, compared to the parental virus. 
Supplementary Materials: The following are available online at http://www.mdpi.com/1999-4915/12/6/615/s1. Figure S1: Infection-transfection controls. Figure S2: Controls for single cell purification via FACS. Figure S3: PCR analysis of recombinant Benin $\Delta$ EP153R $\Delta E P 402 R \Delta D P 148 R$. Table S1: Percentage of mNeonGreen positive cells. Table S2: Percentage of mNeonGreen positive wells.

Author Contributions: Conceptualization, A.R., K.M., A.L.R., L.K.D., methodology, A.R., K.M., A.L.R.; writing A.R., K.M., A.L.R., L.K.D. All authors have read and agreed to the published version of the manuscript

Funding: This research was funded by Biotechnology and Biological Sciences Research Council, Grant Numbers: BBS/E/I/00007031, BBS/E/I/00007034 and BBS/E/I/00007039. Some parts of the quoted research were funded in part by the Bill \& Melinda Gates Foundation and with United Kingdom (UK) Aid from the UK Government through Global Alliance for Livestock Veterinary Medicines (GALVmed) (Grant numbers: OPP1009497, and 203188-101). The findings and conclusions contained within are those of the authors and do not necessarily reflect positions or policies of the Bill \& Melinda Gates Foundation or the UK Government. The funders (Bill \& Melinda Gates Foundation and the UK Government) had no role in study design, data collection and analysis, decision to publish, or preparation of the manuscript.

Acknowledgments: We are grateful to members of the ASFV group at Pirbright for helpful discussions.

Conflicts of Interest: The authors declare no conflict of interest.

\section{References}

1. Netherton, C.L.; Connell, S.; Benfield, C.T.O.; Dixon, L.K. The Genetics of Life and Death: Virus-Host Interactions Underpinning Resistance to African Swine Fever, a Viral Hemorrhagic Disease. Front. Genet. 2019, 10. [CrossRef] [PubMed]

2. FAO. Report on African Swine Fever (ASF) in Asia and the Pacific. In Proceedings of the FAO Regional Conference for Asia and the Pacific, Thimphu, Bhutan, 17-20 February 2020.

3. Arias, M.; De la Torre, A.; Dixon, L.; Gallardo, C.; Jori, F.; Laddomada, A.; Martins, C.; Parkhouse, R.M.; Revilla, Y.; Rodriguez, F.; et al. Approaches and Perspectives for Development of African Swine Fever Virus Vaccines. Vaccines 2017, 5, 35. [CrossRef] [PubMed]

4. Arias, M.; Jurado, C.; Gallardo, C.; Fernández-Pinero, J.; Sánchez-Vizcaíno, J.M. Gaps in African swine fever: Analysis and priorities. Transbound. Emerg. Dis. 2018, 65, 235-247. [CrossRef] [PubMed]

5. Rodríguez, J.M.; Almazán, F.; Viñuela, E.; Rodriguez, J.F. Genetic manipulation of African swine fever virus: Construction of recombinant viruses expressing the $\beta$-galactosidase gene. Virology 1992, 188, 67-76. [CrossRef]

6. Gómez-Puertas, P.; Rodríguez, F.; Ortega, A.; Oviedo, J.M.; Alonso, C.; Escribano, J.M. Improvement of African swine fever virus neutralization assay using recombinant viruses expressing chromogenic marker genes. J. Virol. Methods 1995, 55, 271-279. [CrossRef]

7. Zsak, L.; Lu, Z.; Kutish, G.F.; Neilan, J.G.; Rock, D.L. An African swine fever virus virulence-associated gene NL-S with similarity to the herpes simplex virus ICP34.5 gene. J. Virol. 1996, 70, 8865-8871. [CrossRef]

8. Neilan, J.G.; Lu, Z.; Kutish, G.F.; Zsak, L.; Burrage, T.G.; Borca, M.V.; Carrillo, C.; Rock, D.L. A BIR Motif Containing Gene of African Swine Fever Virus, 4CL, Is Nonessential for Growthin Vitroand Viral Virulence. Virology 1997, 230, 252-264. [CrossRef]

9. Afonso, C.L.; Zsak, L.; Carrillo, C.; Borca, M.V.; Rock, D.L. African swine fever virus NL gene is not required for virus virulence. J. Gen. Virol. 1998, 79, 2543-2547. [CrossRef]

10. Hernaez, B.; Escribano, J.M.; Alonso, C. Visualization of the African swine fever virus infection in living cells by incorporation into the virus particle of green fluorescent protein-p54 membrane protein chimera. Virology 2006, 350, 1-14. [CrossRef]

11. Portugal, R.; Martins, C.; Keil, G.M. Novel approach for the generation of recombinant African swine fever virus from a field isolate using GFP expression and 5-bromo-2'-deoxyuridine selection. J. Virol. Methods 2012, 183, 86-89. [CrossRef]

12. O’Donnell, V.; Holinka, L.G.; Sanford, B.; Krug, P.W.; Carlson, J.; Pacheco, J.M.; Reese, B.; Risatti, G.R.; Gladue, D.P.; Borca, M.V. African swine fever virus Georgia isolate harboring deletions of 9GL and MGF360/505 genes is highly attenuated in swine but does not confer protection against parental virus challenge. Virus Res. 2016, 221, 8-14. [CrossRef] 
13. Borca, M.V.; O’Donnell, V.; Holinka, L.G.; Sanford, B.; Azzinaro, P.A.; Risatti, G.R.; Gladue, D.P. Development of a fluorescent ASFV strain that retains the ability to cause disease in swine. Sci. Rep. 2017, 7, 46747. [CrossRef] [PubMed]

14. Chen, W.; Zhao, D.; He, X.; Liu, R.; Wang, Z.; Zhang, X.; Li, F.; Shan, D.; Chen, H.; Zhang, J.; et al. A seven-gene-deleted African swine fever virus is safe and effective as a live attenuated vaccine in pigs. Sci. China Life Sci. 2020, 63, 623-634. [CrossRef] [PubMed]

15. Abrams, C.C.; Dixon, L.K. Sequential deletion of genes from the African swine fever virus genome using the cre/loxP recombination system. Virology 2012, 433, 142-148. [CrossRef]

16. Borca, M.V.; Holinka, L.G.; Berggren, K.A.; Gladue, D.P. CRISPR-Cas9, a tool to efficiently increase the development of recombinant African swine fever viruses. Sci. Rep. 2018, 8, 1-6. [CrossRef] [PubMed]

17. Chapman, D.A.G.; Darby, A.C.; Da Silva, M.; Upton, C.; Radford, A.D.; Dixon, L.K. Genomic analysis of highly virulent Georgia 2007/1 isolate of African swine fever virus. Emerg. Infect. Dis. 2011, 17, 599-605. [CrossRef]

18. Reis, A.L.; Goatley, L.C.; Jabbar, T.; Sanchez-Cordon, P.J.; Netherton, C.L.; Chapman, D.A.G.; Dixon, L.K. Deletion of the African Swine Fever Virus Gene DP148R Does Not Reduce Virus Replication in Culture but Reduces Virus Virulence in Pigs and Induces High Levels of Protection against Challenge. J. Virol. 2017, 91, e01428-17. [CrossRef]

19. Enjuanes, L.; Carrascosa, A.L.; Moreno, M.A.; Viñuela, E. Titration of African Swine Fever (ASF) Virus. J. Gen. Virol. 1976, 32, 471-477. [CrossRef]

20. Hierholzer, J.; Killington, R. Virus isolation and quantitation. In Virology Methods Manual; Elsevier: Amsterdam, The Netherlands, 1996; pp. 25-46.

21. Shaner, N.C.; Lambert, G.G.; Chammas, A.; Ni, Y.; Cranfill, P.J.; Baird, M.A.; Sell, B.R.; Allen, J.R.; Day, R.N.; Israelsson, M.; et al. A bright monomeric green fluorescent protein derived from Branchiostoma lanceolatum. Nat. Methods 2013, 10, 407-409. [CrossRef]

22. Portugal, R.S.; Bauer, A.; Keil, G.M. Selection of differently temporally regulated African swine fever virus promoters with variable expression activities and their application for transient and recombinant virus mediated gene expression. Virology 2017, 508, 70-80. [CrossRef]

23. World Organisation for Animal Health. Technical Disease Card for African Swine Fever; OIE: Paris, France, 2019; Available online: https:/www.oie.int/animal-health-in-the-world/technical-disease-cards/ (accessed on 30 April 2020).

24. Almazán, F.; Rodríguez, J.M.; Andrés, G.; Pérez, R.; Viñuela, E.; Rodriguez, J.F. Transcriptional analysis of multigene family 110 of African swine fever virus. J. Virol. 1992, 66, 6655-6667. [CrossRef] [PubMed]

25. Cackett, G.; Matelska, D.; Sýkora, M.; Portugal, R.; Malecki, M.; Bähler, J.; Dixon, L.; Werner, F. The African Swine Fever Virus Transcriptome. J. Virol. 2020, 94, e00119-20. [CrossRef] [PubMed]

26. Zhang, X.; Edwards, J.P.; Mosser, D.M. The expression of exogenous genes in macrophages: Obstacles and opportunities. In Macrophages and Dendritic Cells; Humana Press: Totowa, NJ, USA, 2009; pp. 123-143.

27. Warwick, C.A.; Usachev, Y.M. Culture, Transfection, and Immunocytochemical Analysis of Primary Macrophages. In Signal Transduction Immunohistochemistry: Methods and Protocols; Kalyuzhny, A.E., Ed.; Springer: New York, NY, USA, 2017; pp. 161-173. [CrossRef]

28. Hernaez, B.; Alonso, C. Dynamin- and Clathrin-Dependent Endocytosis in African Swine Fever Virus Entry. J. Virol. 2010, 84, 2100-2109. [CrossRef]

29. de León, P.; Bustos, M.J.; Carrascosa, A.L. Laboratory methods to study African swine fever virus. Virus Res. 2013, 173, 168-179. [CrossRef]

30. Kotani, H.; NewtonIII, P.B.; Zhang, S.; Chiang, Y.L.; Otto, E.; Weaver, L.; Blaese, R.M.; Anderson, W.F.; McGarrity, G.J. Improved Methods of Retroviral Vector Transduction and Production for Gene Therapy. Hum. Gene Ther. 1994, 5, 19-28. [CrossRef]

31. Verma, R.S.; Giannola, D.; Shlomchik, W.; Emerson, S.G. Increased Efficiency of Liposome-Mediated Transfection by Volume Reduction and Centrifugation. BioTechniques 1998, 25, 46-49. [CrossRef] [PubMed]

32. Borca, M.V.; Carrillo, C.; Zsak, L.; Laegreid, W.W.; Kutish, G.F.; Neilan, J.G.; Burrage, T.G.; Rock, D.L. Deletion of a CD2-Like Gene, 8-DR, from African Swine Fever Virus Affects Viral Infection in Domestic Swine. J. Virol. 1998, 72, 2881-2889. [CrossRef] 
33. Monteagudo, P.L.; Lacasta, A.; López, E.; Bosch, L.; Collado, J.; Pina-Pedrero, S.; Correa-Fiz, F.; Accensi, F.; Navas, M.J.; Vidal, E.; et al. BA71 $\triangle$ CD2: A New Recombinant Live Attenuated African Swine Fever Virus with Cross-Protective Capabilities. J. Virol. 2017, 91, e01058-17. [CrossRef]

34. Borca, M.V.; O’Donnell, V.; Holinka, L.G.; Risatti, G.R.; Ramirez-Medina, E.; Vuono, E.A.; Shi, J.; Pruitt, S.; Rai, A.; Silva, E.; et al. Deletion of CD2-like gene from the genome of African swine fever virus strain Georgia does not attenuate virulence in swine. Sci. Rep. 2020, 10, 494. [CrossRef]

35. Galindo, I.; Almazán, F.; Bustos, M.J.; Viñuela, E.; Carrascosa, A.L. African Swine Fever Virus EP153R Open Reading Frame Encodes a Glycoprotein Involved in the Hemadsorption of Infected Cells. Virology 2000, 266, 340-351. [CrossRef]

36. Hurtado, C.; Bustos, M.J.; Granja, A.G.; de León, P.; Sabina, P.; López-Viñas, E.; Gómez-Puertas, P.; Revilla, Y.; Carrascosa, A.L. The African swine fever virus lectin EP153R modulates the surface membrane expression of MHC class I antigens. Arch. Virol. 2011, 156, 219-234. [CrossRef] [PubMed]

37. Rodríguez, J.M.; Yáñez, R.J.; Almazán, F.; Viñuela, E.; Rodriguez, J.F. African swine fever virus encodes a CD2 homolog responsible for the adhesion of erythrocytes to infected cells. J. Virol. 1993, 67, 5312-5320. [CrossRef] [PubMed]

38. King, K.; Chapman, D.; Argilaguet, J.M.; Fishbourne, E.; Hutet, E.; Cariolet, R.; Hutchings, G.; Oura, C.A.L.; Netherton, C.L.; Moffat, K.; et al. Protection of European domestic pigs from virulent African isolates of African swine fever virus by experimental immunisation. Vaccine 2011, 29, 4593-4600. [CrossRef] [PubMed]

39. Shaner, N.C.; Lin, M.Z.; McKeown, M.R.; Steinbach, P.A.; Hazelwood, K.L.; Davidson, M.W.; Tsien, R.Y. Improving the photostability of bright monomeric orange and red fluorescent proteins. Nat. Methods 2008, 5, 545-551. [CrossRef] [PubMed]

(C) 2020 by the authors. Licensee MDPI, Basel, Switzerland. This article is an open access article distributed under the terms and conditions of the Creative Commons Attribution (CC BY) license (http://creativecommons.org/licenses/by/4.0/). 